
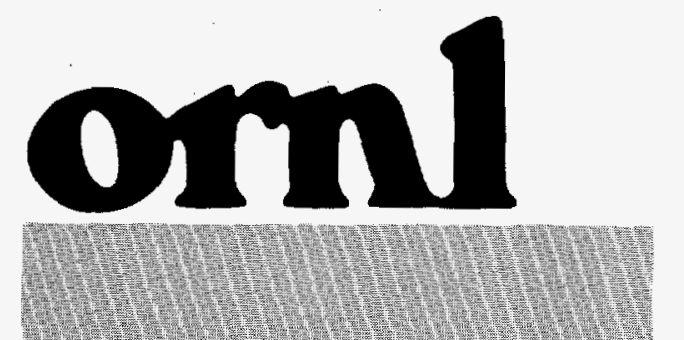

OAK RIDGE

NATIONAL

LABORATORY

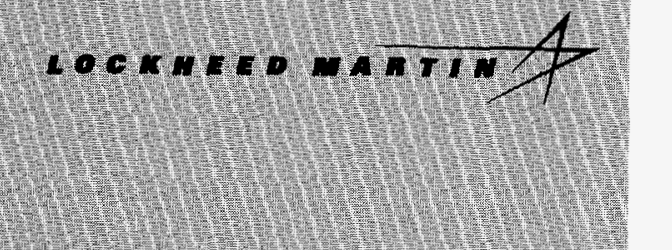

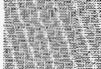
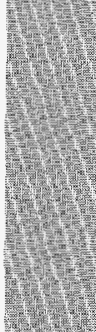

WWAGED AND OPERATED BY

LOEKHEEO WARMI ENEROY RESEA HCH CORPORATHOH FOR THEUTHE STATES

DEPLITUET OF EMERGY

ORNL-27 1305
ORNL/TM-13439

\section{MICROWAVE VERSUS CONVENTIONAL SINTERING OF SILICON CARBIDE TILES}

\author{
M. D. Kass \\ J. B. O. Caughman \\ S. C. Forrester \\ Al Akerman

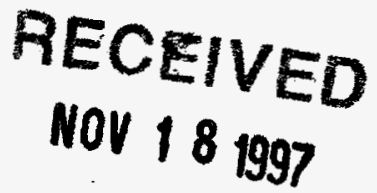 \\ Engineering Technology and \\ Fusion Energy Divisions \\ Oak Ridge National Laboratory \\ P.O. Box 2009 \\ Oak Ridge, TN 38731-8088
}

\section{May 7, 1997}

Prepared for the

Program Manager - Survivable Systems and Army Research Laboratory Weapons Test

Directorate

Department of the Army

Under Interagency Agreement

No. IAG 1969-C101-A1

Prepared by

Oak Ridge National Laboratory,

Oak Ridge, Tennessee 37831-8088

Managed by

Lockheed Martin Energy Research Corp.

For the

U.S. Department of Energy

under contract number DE-AC05-96OR22464

The submitted manuscript has been authored by a contractor of the U.S. Government under contract No. DE-AC05-96OR22464. Accordingly, the U.S. Government retains a nonexclusive, royalty-free license to publish or reproduce the published form of this contribution, or allow others to do so, for U.S.

Government purposes.

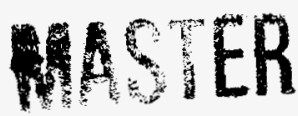




\section{DISCLAIMER}

This report was prepared as an account of work sponsored by an agency of the United States Government. Neither the United States Government nor any agency thereof, nor any of their employees, makes any warranty, express or implied, or assumes any legal liability or responsibility for the accuracy, completeness, or usefulness of any information, apparatus, product, or process disclosed, or represents that its use would not infringe privately owned rights. Reference herein to any specific commercial product, process, or service by trade name, trademark, manufacturer, or otherwise does not necessarily constitute or imply its endorsement, recommendation, or favoring by the United States Government or any agency thereof. The views and opinions of authors expressed herein do not necessarily state or reflect those of the United States Government or any agency thereof. 


\section{DISCLAIMER}

Portions of this document may be illegible electronic image products. Images are produced from the best available original document. 
ORNL/TM-13439

\title{
MICROWAVE VERSUS CONVENTIONAL SINTERING OF SILICON CARBIDE TILES
}

\author{
M. D. Kass \\ J. B. O. Caughman \\ S. C. Forrester \\ Al Akerman \\ Engineering Technology and Fusion Energy Divisions \\ Oak Ridge National Laboratory \\ P.O. Box 2009 \\ Oak Ridge, TN 38731-8088
}

May 7, 1997 


\section{TABLE OF CONTENTS}

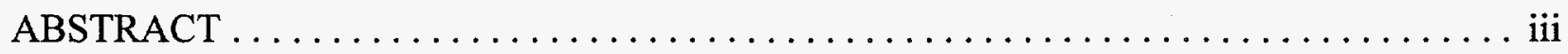

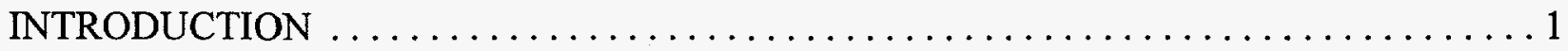

EXPERIMENTAL PROCEDURE $\ldots \ldots \ldots \ldots \ldots \ldots \ldots \ldots \ldots \ldots \ldots \ldots \ldots \ldots$

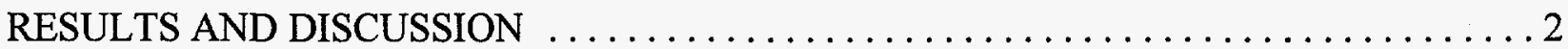

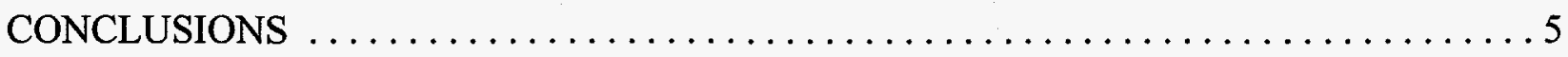

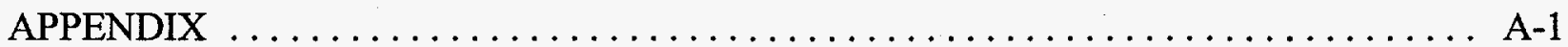




\begin{abstract}
Silicon carbide eutectic green body tiles were sintered at $2100^{\circ} \mathrm{C}$ in argon for one hour using conventional (resistance heating) and microwave techniques. The sample sintered using microwave energy achieved a final density 91.5 percent of theoretical, whereas, the conventionally-treated sample sintered to 84.4 percent of theoretical. In addition, the Poisson's ratio and acoustic moduli (Young's, shear, and bulk) were considerably higher for the microwave-sintered specimen.
\end{abstract}




\section{INTRODUCTION}

Silicon carbide is being evaluated as an armor material because of its lightweight, high-hardness, and excellent armor efficiency. However, one of the problems associated with silicon carbide is the high cost associated with achieving fully dense tiles. Full density requires either hot pressing and sintering or reaction bonding. Past efforts have shown that hot pressed tiles have a higher armor efficiency than those produced by reaction bonded sintering. An earlier study showed that the acoustic properties of fully-dense silicon carbide tiles were enhanced through the use of postsintered microwave heat treatments. One of the least expensive forming techniques is to isostatically press-and-sinter. In this study, we have used microwave energy to densify silicon carbide green bodies. Microwave sintering has been demonstrated to be a very quick way to sinter ceramics such as alumina to exceptionally high densities. Previous work has shown that microwave post treatment of fully-dense reaction bonded silicon carbide tiles significantly improves the acoustic properties of the tiles. These properties include Poisson's ratio, Young's modulus, shear modulus, and bulk modulus.

\section{EXPERIMENTAL PROCEDURE}

Silicon carbide green bodies were provided by Cercom, Inc., for processing at Oak Ridge National Laboratory (ORNL). Yttria and aluminum were added as sintering aids. The green bodies were three inches by three inches by one-inch thick. Prior to sintering, the tile samples were baked at $400^{\circ} \mathrm{C}$ in a conventional furnace to remove organic binders. One sample was heated in a conventional resistance-heated, carbon-lined furnace to $2150^{\circ} \mathrm{C}$ in argon gas for one hour. This sample was loaded inside a carbon crucible and sintered in a vertical position to reduce thermal stresses and, therefore, cracking. The second sample was loaded horizontally inside a boron nitride crucible packed with a mixture of boron nitride and glassy carbon. This was then placed inside a 12-inch alumina fiberboard box for additional insulation. The boron nitride and glassy carbon are necessary to reduce thermal stresses in the silicon nitride part caused by uneven microwave heating. This sample was heated in a $12 \mathrm{~kW}$ microwave furnace at $2100^{\circ} \mathrm{C}$ under argon cover gas for one hour. The heating rate for both specimens was $10^{\circ} \mathrm{C} /$ minute. Both samples were furnace cooled to room temperature.

Physical properties were measured on the tiles using ultrasonic velocity measurements. A total of five readings were taken from the samples at the four corners and at the center as shown in Fig. 1. From the velocity measurements, Poisson's ratio, Young's modulus, shear modulus, and bulk modulus were calculated. Each tile was also scanned ultrasonically to map density uniformity as well as irregularities and flaws, such as cracks, which may be present. 


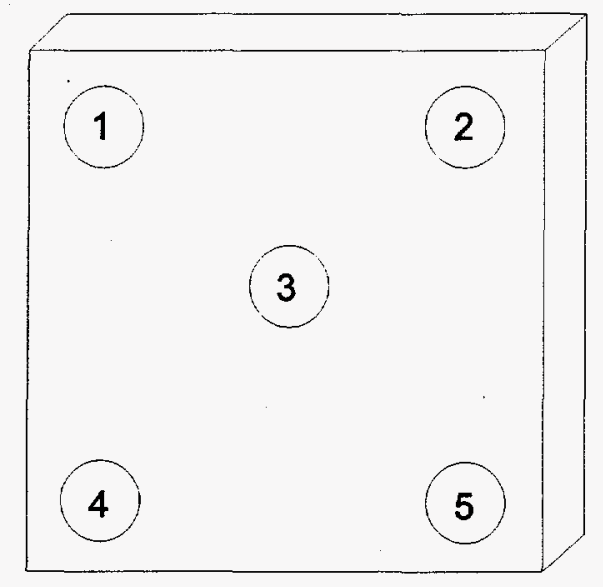

Fig. 1. Location of velocity measurements

\section{RESULTS AND DISCUSSION}

Visual comparison of the tiles after sintering showed that the conventionally-sintered tile was black while the microwave-sintered tile was gray in coloration. The surface of the conventionally-sintered tile was coarser than the microwave-sintered specimen. This coarseness is attributed to the formation of large crystallites on the specimen surface, which is an indication that some vaporization had occured. The microwave-sintered specimen had a smoother surface but contained a $1.5 \mathrm{~cm}$ crack which ran perpendicular to one side, which can be seen in the ultrasonic scan (Fig. 2). This crack was likely caused by uneven heating of the sample by the microwave field.

The sintered results are shown in Table 1. For each specimen the post sintered mass was less than the starting (post bake-out) mass, which indicates that volatization of the silicon carbide had taken place. The conventionally and microwave-sintered specimens lost 28 and 22 grams of mass, respectively. This indicates that excessive volatilization occured during both sintering processes. The higher mass-loss for the conventionally-sintered tile was likely due to the higher sintering temperature $\left(2150^{\circ} \mathrm{C}\right)$. As shown in the table, the sample undergoing microwave sintering densified to a significantly higher density than the conventionally-sintered sample even though the sintering temperatures and heating rates were essentially the same. These data suggest that microwave sintering techniques may be better than conventional sintering techniques for densifing silicon carbide. However, the uneven heating caused by the microwave field may create internal stresses in silicon carbide bodies that may lead to cracking. This is a very promising result for a beginning sintering attempt. Similiar cracks in other materials have 


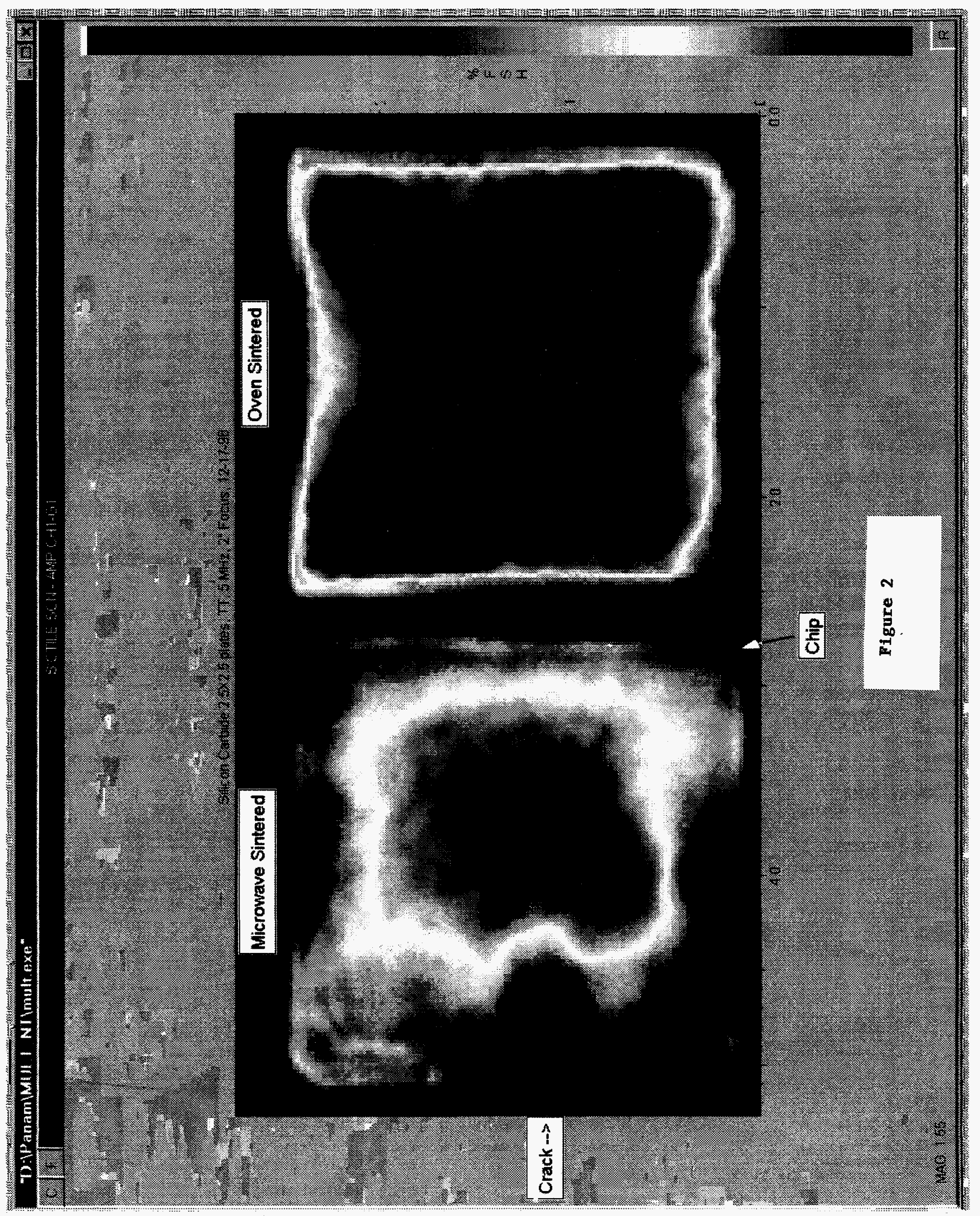


been eliminated through process refinements. Efforts to improve the uniformity of the microwave field would likely decrease the probability of cracking while maintaining high densification.

Table 1. Results of silicon carbide sintered using conventional and microwave techniques

\begin{tabular}{|l|l|l|l|l|l|}
\hline $\begin{array}{l}\text { Sample Sintering } \\
\text { Process }\end{array}$ & $\begin{array}{l}\text { Green } \\
\text { mass }(\mathrm{g})\end{array}$ & $\begin{array}{l}\text { Bake-out } \\
\text { mass }(\mathrm{g})\end{array}$ & $\begin{array}{l}\text { Sintered } \\
\text { Mass }(\mathrm{g})\end{array}$ & $\begin{array}{l}\text { Sintered } \\
\text { Volume }\left(\mathrm{cm}^{3}\right)\end{array}$ & $\begin{array}{l}\text { Density } \\
(\% \text { of theoretical })\end{array}$ \\
\hline Microwave & 258.36 & 246.94 & 224.81 & 76.40 & 91.5 \\
\hline Conventional & 255.79 & 244.48 & 216.56 & 80.19 & 84.4 \\
\hline
\end{tabular}

As shown in Table 2, the calculated acoustic properties are much higher for the sample that was sintered using microwave energy than for the sample that was conventionally sintered. Poisson's ratios for both specimens were found to be much higher than normal for silicon carbide. The typical value of Poisson's ratio for sintered silicon carbide is 0.14 . The higher values obtained from the samples are likely due to the addition of Yttria and aluminum as sintering aids. These sintering aids were necessary when using pressureless sintering techniques such as those used in this study. The increase in Poisson's ratio was 16 percent higher for the microwave-sintered specimen, and the acoustic moduli were also much higher. The values obtained for the Young's, shear, and bulk moduli for the microwave-treated sample compare well with literature values of silicon carbide formed by both sintering and reaction bonding methods, but the values obtained for the conventionally-sintered sample were considerably lower. The Young's and shear moduli were 50 percent higher for the microwave-sintered sample, and the bulk modulus was over 100 percent higher. In addition, the standard deviations for the microwave-processed sample were much lower than the conventionally-processed specimen indicating better uniformity. The higher acoustic properties for the microwave-sintered sample likely resulted from the much higher density of the post sintered tile. For a full treatment of the acoustic properties see the Appendix. 
Table 2. Acoustic property measurements

\begin{tabular}{|l|l|l|}
\hline Ultrasonic Property Measured & $\begin{array}{l}\text { Conventionally } \\
\text { Sintered Sample }\end{array}$ & $\begin{array}{l}\text { Microwave-Sintered } \\
\text { Sample }\end{array}$ \\
\hline Poisson's Ratio & $0.289 \pm 0.016$ & $0.336 \pm 0.008$ \\
\hline Young's Modulus, GPa & $234.075 \pm 7.048$ & $369.020 \pm 2.717$ \\
\hline Shear Modulus, GPa & $90.823 \pm 2.460$ & $138.156 \pm 1.275$ \\
\hline Bulk Modulus, GPa & $185.682 \pm 18.555$ & $374.623 \pm 17.349$ \\
\hline
\end{tabular}

\section{CONCLUSIONS}

Microwave sintering of silicon carbide containing sintering aids produces a denser and more uniform solid than silicon carbide, which is densified using the conventional press-and-sintering method. Volatilization of the part was also reduced by microwave heating. Physical properties such as acoustic moduli and Poisson's ratios were substantially higher for silicon carbide sintered using microwave radiation. 


\section{External Distribution}

1. Dr. William J. Bruchey, Army Concepts Section, AMSRL-WT-TA, Armor Mechanics Branch, Terminal Effects Division, Aberdeen Proving Ground, MD 21005-5066.

2. J. Bulmash, Armor Concepts Section, AMSRL-WT-TA, Armor Mechanics Branch, Terminal Effects Division, Aberdeen Proving Ground, MD 21005-5066.

3. Terrance M. Dean, Chief, Tech Mangement Division, Project Manager, Survivability Systems Warren, MI 48397-5000.

4. Edward J. Rapacki, Armor Technical Team, AMSRL-WT-TA, Weapons Technology Directorate, Aberdeen Proving Ground, MD 21005-5066.

5. John C. Rowe, Senior Project Engineer, U. S. Army, Project Manager, Survivability Systems, Warren, MI 48397-5000.

\section{Internal Distribution}

6-16. M. A. Akerman

17. J. B. Caughman

18. R. M. Davis

19. S. C. Forrester

20. M. D. Kass

21. R. M. Schilling

22. Central Research Library

23. Laboratory Records - RC

24-25. OSTI (to be forwarded by Laboratory Records) 


\section{APPENDIX}

\section{Ultrasonic Material Analysis Report ( UMAT Version 4.0.1) $12 / 17 / 96$ \\ Part Calibrated with Standard Report}

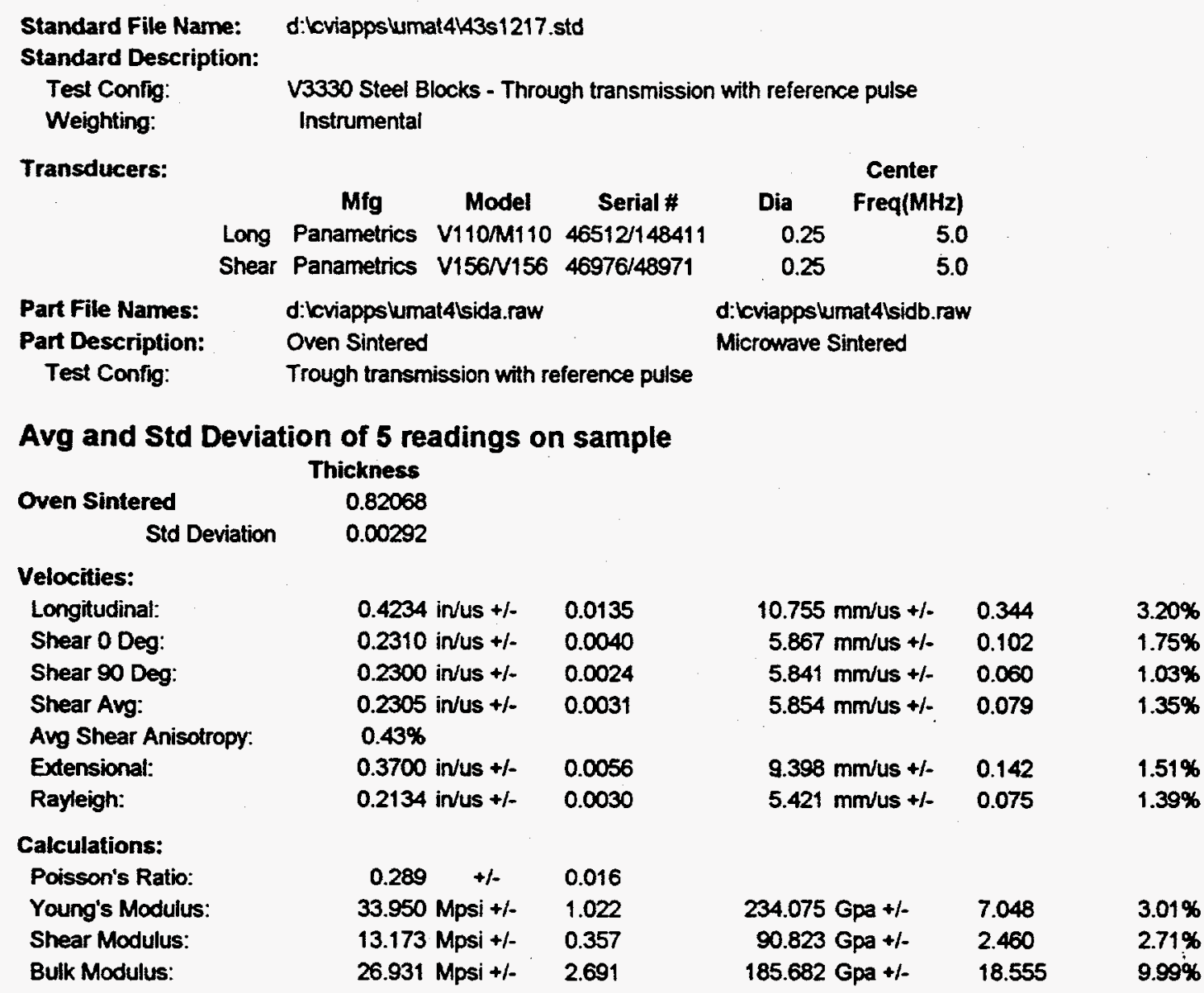

Avg and Std Deviation of 5 readings on sample Thickness

$\begin{array}{cc}\text { Microwave Sintered } & 0.78722 \\ \text { Std Deviation } & 0.00139\end{array}$

Velocities:

Longitudinal:

Shear 0 Deg:

Shear 90 Deg:

Shear Avg:

Avg Shear Anisotropy:

Extensional:

Rayleigh:

$\begin{array}{ll}0.5373 \text { in/us }+/- & 0.0080 \\ 0.2678 \text { in/us }+/- & 0.0007 \\ 0.2666 \text { in/us }+/- & 0.0029 \\ 0.2672 \text { in/us }+/- & 0.0012 \\ 0.43 \% & \\ 0.4366 \text { in/us }+1- & 0.0016 \\ 0.2492 \text { in/us }+1- & 0.0010\end{array}$

Calculations:

Poisson's Ratio:

Young's Modulus:

Shear Modulus:

Bulk Modulus:

$\begin{array}{cc}0.336+1- & 0.008 \\ 53.522 \text { Mpsi }+/- & 0.394 \\ 20.038 \text { Mpsi }+1- & 0.185 \\ 54.335 \text { Mpsi }+1- & 2.516\end{array}$

$\begin{array}{rrr}13.647 \text { mm/us +/- } & 0.203 & 1.49 \% \\ 6.801 \mathrm{~mm} / \mathrm{us}+/- & 0.017 & 0.25 \% \\ 6.772 \mathrm{~mm} / \mathrm{us}+1- & 0.072 & 1.07 \% \\ 6.786 \mathrm{~mm} / \mathrm{us}+/- & 0.031 & 0.46 \% \\ & & \\ 11.091 \mathrm{~mm} / \mathrm{us}+/- & 0.041 & 0.37 \% \\ 6.330 \mathrm{~mm} / \mathrm{us}+/- & 0.026 & 0.40 \%\end{array}$

$369.020 \mathrm{Gpa}+1-\quad 2.717 \quad 0.74 \%$

$138.156 \mathrm{Gpa}+/-\quad 1.275 \quad 0.92 \%$

$374.623 \mathrm{Gpa}+1-\quad 17.349 \quad 4.63 \%$ 